\title{
Observations of near surface wind speed, temperature and radiative budget at Dome C, Antarctic Plateau during 2005
}

\author{
STEFANIA ARGENTINI, ILARIA PIETRONI, GIANGIUSEPPE MASTRANTONIO*, ANGELO P. VIOLA, \\ GUILLAUME DARGAUD and IGOR PETENKO \\ ISAC-CNR, Via del Fosso del Cavaliere, 10000133 Roma, Italy \\ *Corresponding author: g.mastrantonio@isac.cnr.it
}

\begin{abstract}
The annual and diurnal behaviours of near surface wind speed, temperature, and the radiative budget at Concordia Station (Dome C) in different seasons are shown. The wind speed was lowest in summer when a daily cycle was also observed. The largest mean values were concurrent with boundary layer growth in the afternoon. In winter and spring the wind speed reached the highest mean values. Perturbations in the wind flow were due to warming events which occurred periodically at Dome $\mathrm{C}$. The lowest temperatures were in April and at the end of August. The coreless winter behaviour was perturbed by warming events which in many cases produced an increase in temperature of $c .20^{\circ} \mathrm{C}$. The average temperature profiles show permanent thermal inversion, with the exception of a few hours in the afternoons during the summer. The strongest ground-based thermal inversions were observed in the polar winter. The largest potential temperature gradients were limited to a $30-40 \mathrm{~m}$ deep layer close to the surface. The net radiation was negative almost all the time with the exception of the period from mid-December to mid-January.
\end{abstract}

Received 7 August 2012, accepted 8 March 2013, first published online 17 June 2013

Key words: Concordia, radiation temperature, surface-layer meteorology, wind measurements

\section{Introduction}

Due to its remoteness and difficult access, relatively little is known about the processes occurring in the interior of the Antarctic continent. In the long Antarctic winter, with no solar radiation, the surface cools continuously through upward net longwave radiation, which is favoured by clear sky conditions and the cold and dry atmosphere. Such energy loss is partially balanced by the turbulent and sub-surface heat fluxes which extract heat from both the atmosphere and the ice sheet, cooling the surface air and ice. As a consequence of this radiative cooling process, strong surface-based temperature inversions develop. Phillpot \& Zillman (1970) studied the climatology of these temperature inversions across the Antarctic continent. They found that the inversions over the South Pole reached an average of c. $20^{\circ} \mathrm{C}$ in winter, while those over the highest parts of the plateau reached an average of $25^{\circ} \mathrm{C}$. Connolley (1996) provided an overview of the temperature inversions at 21 Antarctic stations, three of which were in the interior. Following on from the study by Jouzel \& Merlivat (1984), Connolley (1996) derived a regression between the surface temperature and the inversion strength, indicating the dependence of this relationship on the terrain slope. Other investigations into the correlation between the near-surface winds and the temperature inversions were carried out by Hudson \& Brandt (2005), Dalrymple (1966),
Lettau \& Schwerdtfeger (1967) and Pietroni et al. (2012). In the presence of a surface slope, the denser and colder masses of the air adjacent to the surface are forced down-slope, and deflected to the left by the Coriolis force. As a result, katabatic winds occur. The katabatic wind regime is occasionally interrupted by the horizontal advection of warm air masses from the coast, or by strong large-scale winds.

During the Antarctic summer, the absorption of shortwave radiation produces a diurnal cycle in the behaviour of the atmospheric boundary layer. Although the amount of solar radiation available to heat the surface is limited by the high surface albedo, the surface heating leads to a weak thermal mixing with the formation of a convective boundary layer during the daytime (Mastrantonio et al. 1999, Argentini et al. 2005, King et al. 2006, Zhou et al. 2009).

Reliable measurements of the radiative budget at the surface of the Antarctic ice sheet are essential in order to assess the role of Antarctica as a heat sink in the Earth's climate, for the ground truth of satellite observations (e.g. to distinguish between clouds and the snow surface) and to validate atmospheric models (King \& Connolley 1997). These measurements can also be used to develop the albedo parameterisations for dry snow, the parameterisation of radiative processes, and ice dynamical models (Van den Wal \& Oerlemans 1997). A reliable estimate of the surface energy balance is not possible without an accurate 


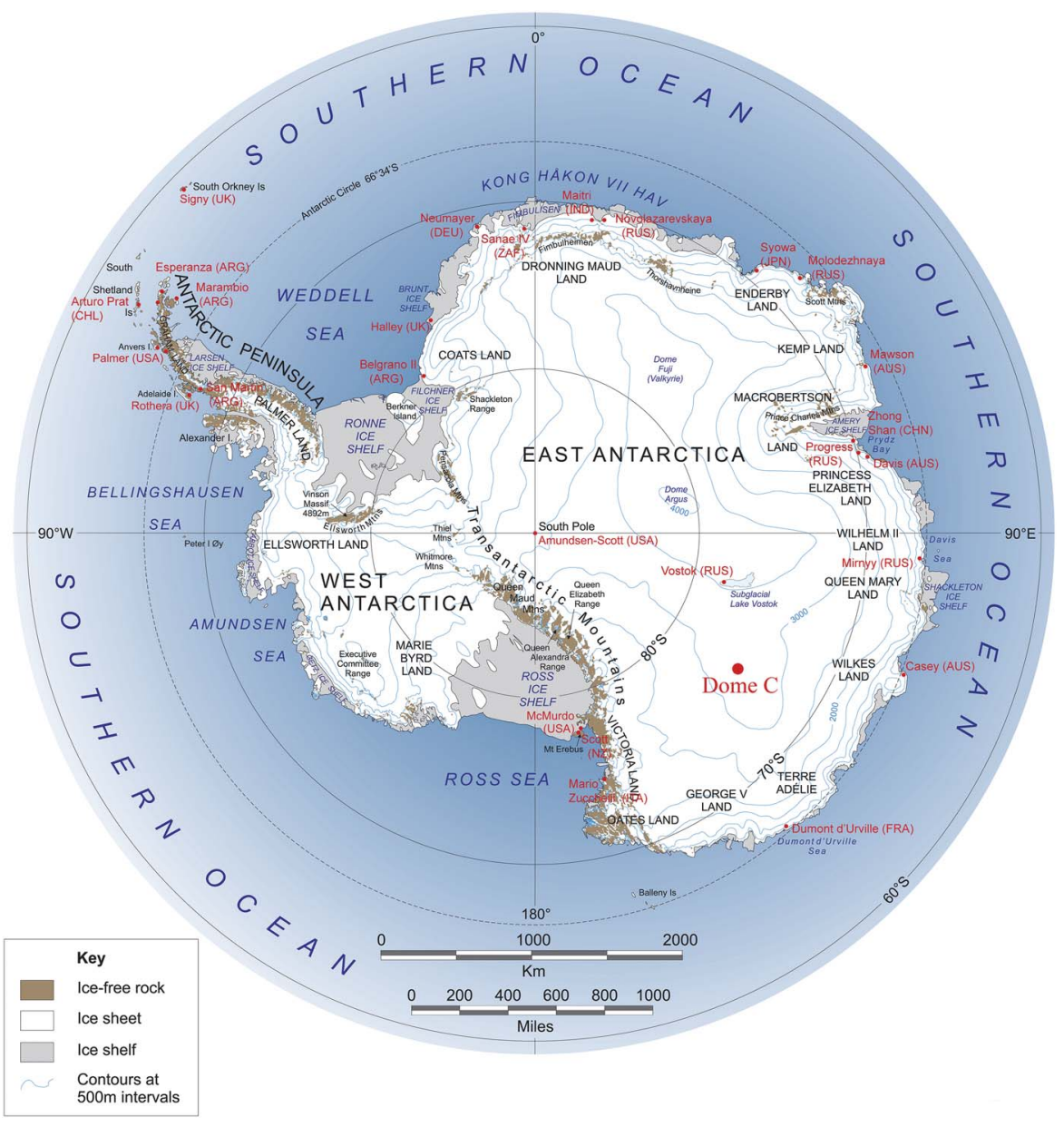

Fig. 1. Position of Concordia station at Dome C in Antarctica. measurement of the radiation components (Bintanja \& Van den Broeke 1995, Van As et al. 2005a, 2005b), which can be affected by several features relating to the properties of the snow and the sun elevation angle.

Due to the high surface albedo and the prolonged periods of darkness, the outgoing longwave radiation dominates the surface heat budget in Antarctica. The Antarctic atmosphere is highly transmissive to solar radiation, especially in the high interior plateau where the atmosphere is thin and the concentrations of clouds, water vapour and aerosol are low. Even in full summer, when the solar zenith angles are large, the fine-grained, dry, clean snow surface absorbs only 5-25\% of the incoming shortwave radiation (Carroll \& Fitch 1981). On the other hand, the snow, like most natural surfaces, has a high infrared emissivity $(\approx 0.98)$ (Wiscombe \& Warren 1980), so that it effectively loses heat in the form of longwave radiation. Combined with an atmosphere that is cold, dry, thin, clear and clean, this leads to a pronounced (longwave and all-wave) radiation deficit at the surface in winter. Such loss of energy makes the Antarctic ice sheet a major heat sink in the Earth's atmosphere and introduces a strong coupling between the radiation balance and the nearsurface climate (Dutton et al. 1991, Stanhill \& Cohen 1997). A proper representation of the present-day surface energy balance is a necessary prerequisite for any model that has to produce useful climate predictions. Consequently, it is important for all the surface energy fluxes to be validated in detail (King \& Connolley 1997). Only a few attempts have been made to validate General Circulation Model (GCM) surface energy balance computations, largely because surface energy balance measurements are only available for a limited number of stations worldwide and measurements at these locations may only be representative of a small area around the station rather than a region of comparable size to a GCM grid square.

The comparison of the modelled surface energy fluxes with the observations at Antarctic stations has shown that the shortwave radiative modelled fluxes are in reasonable agreement with the observations, but also that the downward flux of longwave radiation is consistently too small (King \& Connolley 1997). The study by Wild et al. (1995) showed that this problem is common to many different parts of the world, but is likely to be greater in Antarctica than elsewhere.

Finally, we mention the increasing interest of astronomers in the Dome $\mathrm{C}$ site. Because of the extremely low temperatures and humidity, and the high elevation, the Antarctic plateau is a potentially ideal site for astronomical 


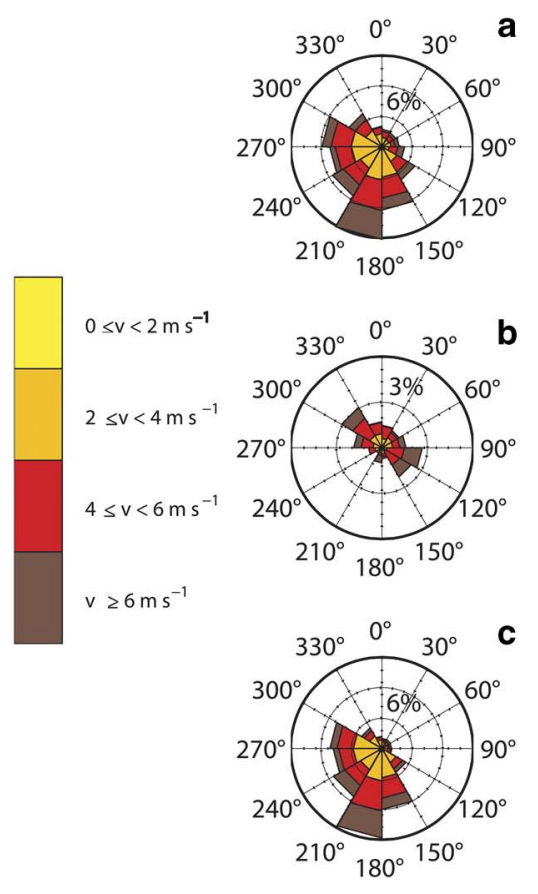

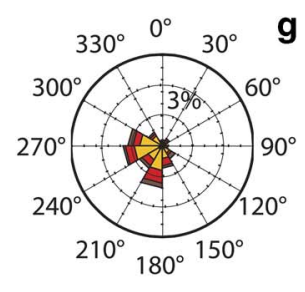
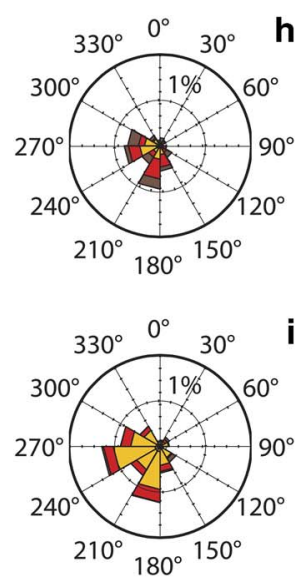

Fig. 2. Wind rose of the hourly averaged wind speed for different velocity ranges during 2005. a. All measurements, b. only days with warming events, and c. all measurements without days with warming events. d. All winter measurements, e. winter days with warming events, and $\mathbf{f}$. winter measurements without days with warming events. g. All summer measurements, h. summer (morning/ afternoon: 10h00-16h00 local standard time (LST)), and i. summer (night/ early morning: 22h00-06h00 LST). All graphs are normalized to 2005 wind measurements. observations, which would otherwise only be possible in space. For this reason, in recent years, the optical turbulence over the Antarctic plateau has been a subject of studies by astronomers (Lawrence et al. 2004, Aristidi et al. 2005b, Hagelin et al. 2008, Lascaux et al. 2009). The intensity of the optical turbulence depends on the vertical gradients of the wind velocity and on the strength of the temperature inversion (Marks et al. 1999, Geissler \& Masciadri 2006).

This paper reports on observations made with a sonic anemometer and a microwave radiometer during an atmospheric field experiment carried out in the period 2004-05 at Dome C in East Antarctica, where the FrenchItalian plateau station of Concordia is located. This was the first year that Concordia Station was open during winter.

\section{Site, climatological setting and instrumentation}

Concordia is a permanent station located at Dome C, Antarctica $\left(74.1^{\circ} \mathrm{S}, 123.3^{\circ} \mathrm{E}, 3233 \mathrm{~m}\right.$ above sea level), on the East Antarctic Plateau c. $1000 \mathrm{~km}$ from the nearest coastline (Fig. 1). It is jointly operated by the French IPEV (Institute Polaire Français Paul-Émile Victor) and the Italian PNRA (Programma Nazionale Ricerche in Antartide). Dome $\mathrm{C}$ is located on a regional topographic maximum on the plateau where the local slopes do not exceed $1 \%$.

Strong and long-lived ground based inversions occur at Dome $\mathrm{C}$ almost all the time, except during the summer in the hours of maximum insolation when the net radiation is positive. The almost permanent condition of atmospheric thermal inversion contributes to the formation of a large and cold air basin, which generates and sustains the katabatic winds which are observed in the confluence zones around the East Antarctic coast. The cloud cover above Dome $\mathrm{C}$ is usually low because the cloud cover and precipitation decrease when moving inland from the coast, and the level of the occurrence of active weather systems reaching the plateau is low (King \& Turner 1997).

Argentini et al. (2001) have shown that warming events are periodically observed at Dome C during winter. During these events the surface temperature sometimes reaches the values recorded in summer. Coincident with warming events, the wind direction varies and changes from the southern sector $\left(180^{\circ}\right.$ is the most frequent wind direction) to the northern one $\left(0^{\circ}\right.$ from the coast $)$ due to the advection of warm air from the coast and to cloud formation.

Measurements of the wind, temperature at $3 \mathrm{~m}$ and radiative fluxes were made during the period 5 November 2004-13 January 2006 in the framework of the STABLEDC (Study of the Atmospheric Boundary Layer Environmental at Dome C) project. High frequency observations of the three wind components and sonic temperature were made with a Metek USA-1 sonic thermo-anemometer (sampling frequency $10 \mathrm{~Hz}$ ) installed $3.6 \mathrm{~m}$ above the snow surface. To study the near surface atmospheric temperature the Dome $\mathrm{C}$ automatic weather station (AWS) measurements at $3 \mathrm{~m}$ were used. The components of the longwave and shortwave radiations were measured with Kipp \& Zonen pyrgeometers and pyranometers installed $1 \mathrm{~m}$ above the snow surface. A passive microwave radiometer (MTP - 5P Meteorological Temperature Profiler) (Kadygrov \& Pick 1998, Argentini \& Pietroni 2010) was used for the remote measurement of the air temperature profile. A detailed description of the instrumentation, the measurements, and data validation is reported in Argentini \& Pietroni (2010). Since the 

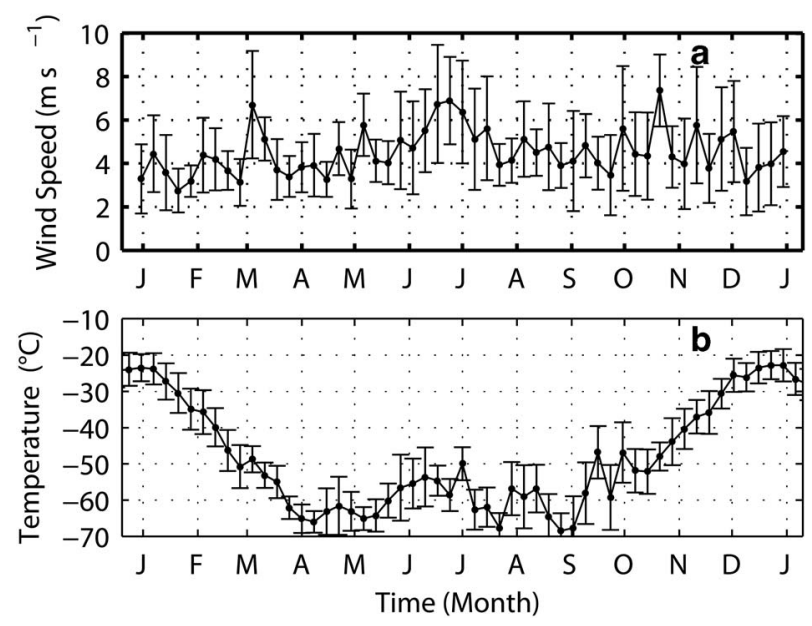

Fig. 3. Annual cycle of weekly-averaged a. wind speed, and b. temperature during the STABLEDC project. The vertical bars represent the standard deviation of the one-houraveraged values.

dominant wind direction is from SSE-SSW, the instrumentation was located $1 \mathrm{~km}$ south of the Concordia buildings to ensure an unobstructed flow of the wind over the measurement site.

In this paper, unless otherwise mentioned, the measurements are given at local standard time (LST). By "night-time" and "nocturnal" we refer to the periods of negative radiative budget. The "seasons" are defined as in Argentini \& Pietroni (2010): first summer, 15 November
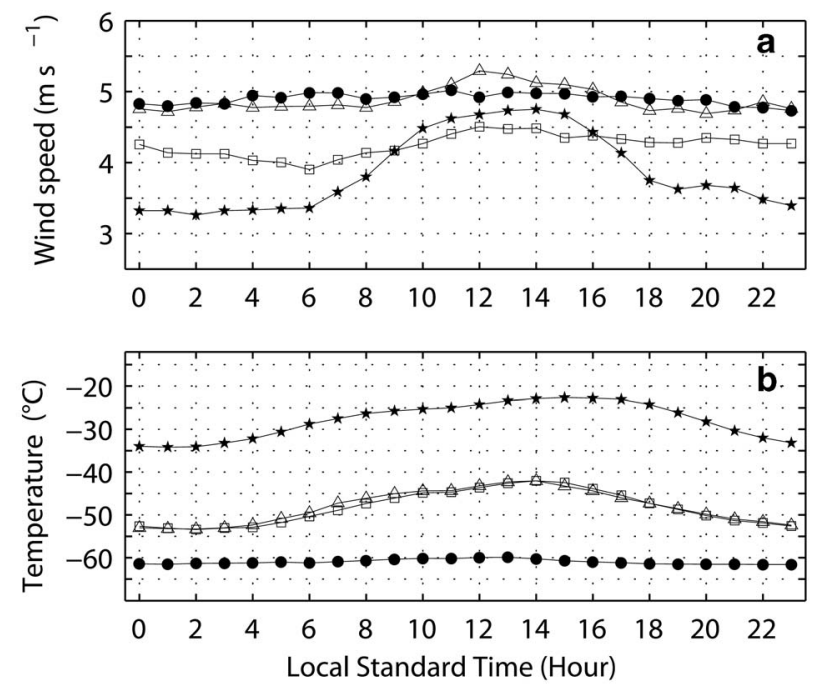

¿ SUMMER $\longrightarrow$ AUTUMN $\longrightarrow$ WINTER $\longrightarrow \triangle$ SPRING

Fig. 4. Diurnal behaviour of hourly-averaged a. wind speed, and b. temperature during summer (full star), autumn (square), winter (full dot) and spring (triangle) during the STABLEDC project.

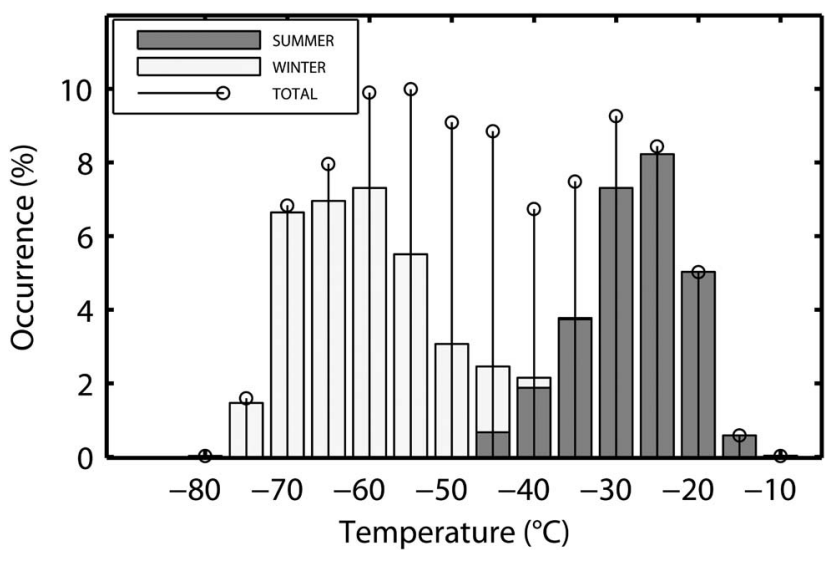

Fig. 5. Histogram of the temperature during 2005.

2004-1 February 2005; second summer, 15 November 2005-13 January 2006; autumn, 1 February-1 April 2005; winter, 1 April-15 September 2005; and spring, 15 September-15 November 2005. In what follows, unless otherwise stated, we consider only measurements of 2005 to avoid biases due to the larger number of summer measurements.

\section{Wind speed and temperature}

The behaviour of the wind and the temperature for the period under investigation has been shown by Argentini \&

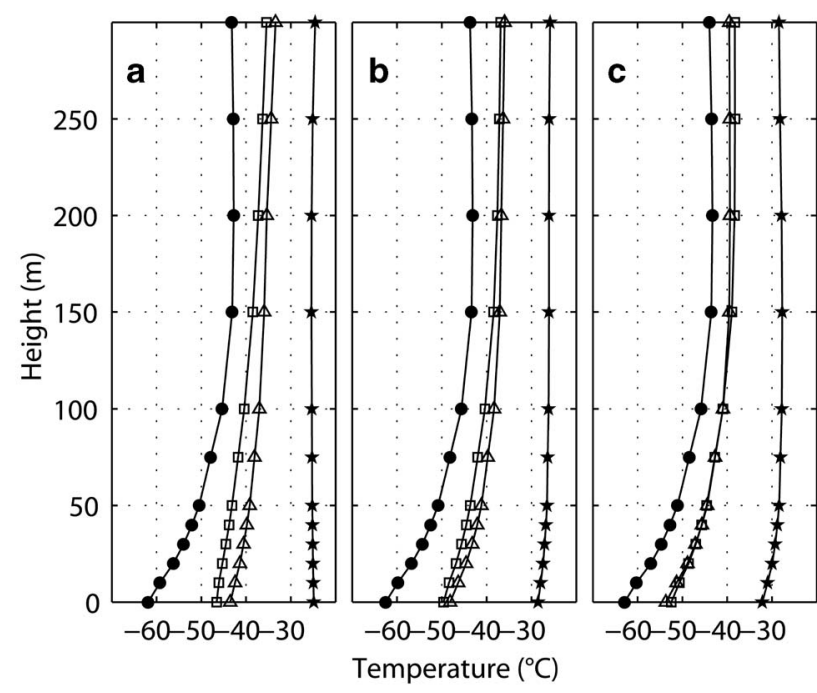

Fig. 6. Temperature profiles during the STABLEDC project:

a. diurnal-average (10h00-14h00 local standard time (LST)),

b. daily-average (00h00-24h00 LST), and c. nocturnal-average (22h00-02h00 LST), in summer (star), autumn (square), winter (dot) and spring (triangle). 
Pietroni (2010). During 2005 the mean wind speed was $4.4 \mathrm{~m} \mathrm{~s}^{-1}$, with extreme values up to $12 \mathrm{~m} \mathrm{~s}^{-1}$. The mean temperature was $-50^{\circ} \mathrm{C}$. The lowest temperatures $\left(-72^{\circ} \mathrm{C}\right.$ minimum value) were observed during winter while the highest temperatures $\left(-29^{\circ} \mathrm{C}\right.$ maximum value) were observed during summer.

\section{Wind speed}

To study the wind regime at Dome $\mathrm{C}$ the probability distributions of the hourly averaged wind speed at $3 \mathrm{~m}$, in $30^{\circ}$ intervals, were calculated. Figure 2 a (all year) shows that in $60 \%$ of all cases the $150^{\circ}-300^{\circ}$ sector was the preferred wind direction. This was also the sector where the strongest winds $\left(>4 \mathrm{~m} \mathrm{~s}^{-1}\right)$ were observed. These winds, which blow from the inner regions of the continent, are low-intensity drainage flows blowing from the highest plateau south of Dome C. Figure 2b (only warming events) shows that the large-scale flow is from the $300^{\circ}-330^{\circ}$ and $90^{\circ}-150^{\circ}$ sectors (from the eastern and western coasts). Figure 2c shows all measurements without days with the warming events. Similar distributions, apart for the flow from the $240^{\circ}-270^{\circ}$ sector, which was associated mainly with the summer, were observed for the winter period (Fig. 2d-f). If the warming events are not included, winds from the $180^{\circ}-210^{\circ}$ sector prevailed (Fig. 2f), and the surface wind direction was scarcely influenced by the largescale motions because of the decoupling due to the strong ground-based temperature inversions. During the winter warming events, large-scale motions were observed $\left(300^{\circ}-330^{\circ}\right.$ and $90^{\circ}-150^{\circ}$ sectors; winds from the coasts) (Fig. 2e) because of the weakening of the ground-based inversion due to an increase in surface temperature caused by longwave heating and/or the vertical mixing. Comparing Fig. 2 (b \& e) we conclude that almost all the warming events occurred during the winter. During the summer the ground-based inversions were less strong, a weak convection was observed in the warmest hours of the day and winds from the $180^{\circ}-300^{\circ}$ sector prevailed (Fig. $2 \mathrm{~g}$ ). The strongest winds were observed during the day (Fig. 2h) due to the increase in the momentum flux transfer from the free atmosphere to the surface layer as a result of a convective boundary layer growth. Winds from the $180^{\circ}-210^{\circ}$ sector were associated with the coldest part of the day when a surface inversion developed and drainage flow circulation took place (Fig. 2i). The main difference, compared with wintertime, was the lack of winds from the $90^{\circ}-150^{\circ}$ sector.

Figure 3 shows the annual behaviour of the weeklyaveraged wind speeds and temperatures. The wind speed values oscillated around $c .4 \mathrm{~m} \mathrm{~s}^{-1}$. The lowest wind speeds occurred during the summer while the highest wind speeds $\left(>6 \mathrm{~m} \mathrm{~s}^{-1}\right)$ were observed during winter (in the months of June and July) and in March and October. As seen from the wind roses, these values mostly occurred in the presence of warming events or drainage flows.
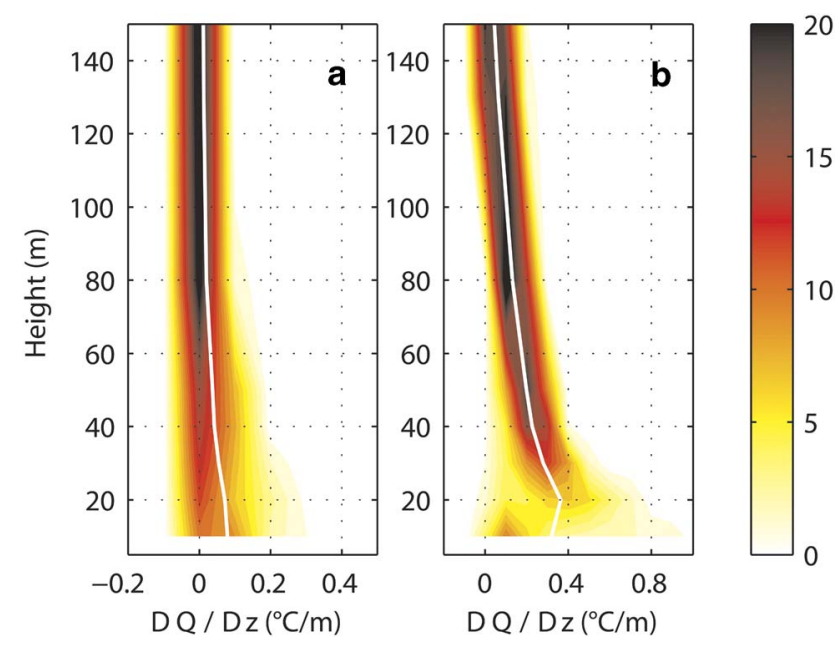

Fig. 7. Occurrence distribution of potential temperature gradients during the STABLEDC project in a. summer, and $\mathbf{b}$. winter. The numbers to the right of the colour bar are proportional to the occurrence value associated with each colour.

The daily cycle of hourly-averaged wind speeds and temperatures during summer, autumn, winter and spring are shown in Fig. 4. During winter and spring, the wind speed was fairly constant throughout the day, with values between $4.5 \mathrm{~m} \mathrm{~s}^{-1}$ and $5 \mathrm{~m} \mathrm{~s}^{-1}$ (standard deviation around $0.5 \mathrm{~m} \mathrm{~s}^{-1}$ ). In autumn, the wind speed varied between 4 and $4.5 \mathrm{~m} \mathrm{~s}^{-1}$ (standard deviation around $0.5 \mathrm{~m} \mathrm{~s}^{-1}$ ). The lowest wind velocities and the strongest diurnal cycle were observed during summer. As shown by King et al. (2006), little variation in wind speed occurred between $19 \mathrm{~h} 00$ and $06 \mathrm{~h} 00$ LST during summer. After 06h00 LST, the wind speed gradually increased until noon, when it reached c. $1.5 \mathrm{~m} \mathrm{~s}^{-1}$ higher than it was at $06 \mathrm{~h} 00 \mathrm{LST}$. The wind speed remained fairly constant until $15 \mathrm{~h} 00$ LST, after which it decreased at a slightly faster rate than the one at which it increased during the morning, reaching its "night-time" value at around $18 \mathrm{~h} 00$ LST. The diurnal variation in the surface wind speed observed at Dome $\mathrm{C}$ during summer was due to an increase in the momentum flux transfer from the free atmosphere to the surface layer as a result of convective boundary layer growth.

\section{Temperature}

The histogram of temperature measured by the Dome C AWS is shown in Fig. 5. The figure shows two local maxima separated by a minimum near $-40^{\circ} \mathrm{C}$. The two maxima were centred at $c .-60^{\circ} \mathrm{C}$ and $-30^{\circ} \mathrm{C}$. The former maximum included the temperatures observed during winter, while the latter maximum corresponded to the summer values.

Figure $3 b$ shows the time series of the weekly-averaged temperatures. A strong seasonal cycle is evident. The temperature reached $-20^{\circ} \mathrm{C}$ during the short summer, and 


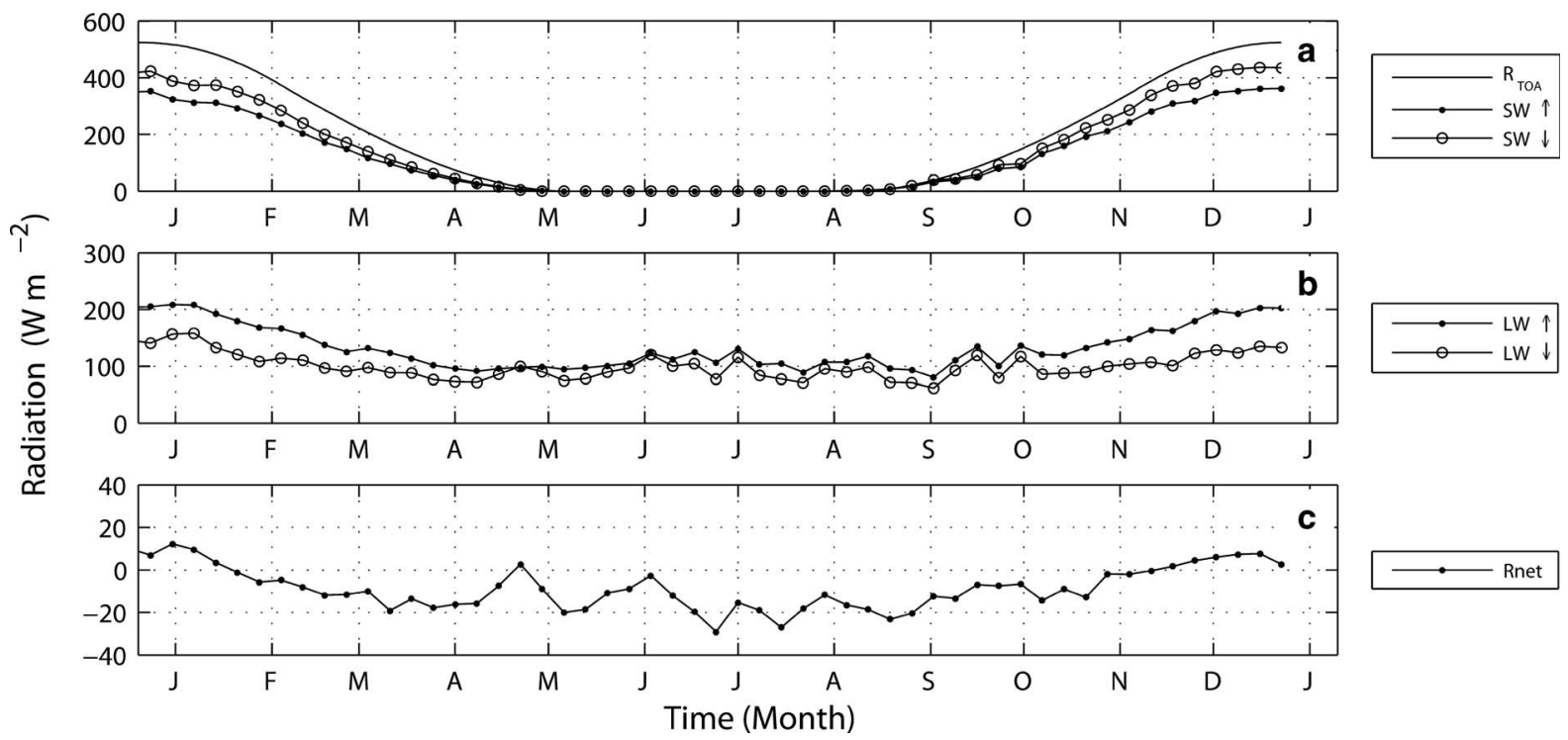

Fig. 8. Annual cycle of weekly-averaged values of a. $\mathrm{R}_{\mathrm{TOA}}$ (solid line), $\mathrm{SW} \uparrow(\mathrm{dot}), \mathrm{SW} \downarrow$ (square), b. $\mathrm{LW} \uparrow($ dots), $\mathrm{LW} \downarrow$ (circle), and c. Rnet during the STABLEDC project.

fell to $-70^{\circ} \mathrm{C}$ during the long coreless winter. The general structure of the coreless winter was modified by warming events occurring in the months of June, July and August. At the beginning of July an average increase of $15^{\circ} \mathrm{C}$ was observed. Argentini et al. (2001) showed that, during these events, the temperature could increase by more than $10^{\circ} \mathrm{C}$ and could persist for about five days with a periodicity of about 15 days. Carroll (1982), Stone et al. (1990), Stone \& Kahl (1991) and Stone (1993) found that at South Pole these warming events generally occurred in the presence of clouds. Neff (1999), by analysing the periods of cooling and warming at the South Pole, has correlated these phenomena to the variation in the wind direction above the boundary layer, sometimes accompanied by advection of clouds from the west or from the Weddell Sea. Carroll (1982) has suggested two possible mechanisms: the advection of warm air, and/or the vertical mixing of air from different layers. Ohtake (1978), analysing particle trajectories across Antarctica, showed that the process of warming was mostly due to the intrusion of warm and moist air and to the condensation nuclei which originate from the Weddell Sea, producing a wide variety of cloud types. Schwerdtfeger \& Weller (1977) have related the surface warming to the variation of longwave radiation emitted by the clouds associated with the moist air present in the upper part of the atmosphere.

Figure $4 \mathrm{~b}$ shows the daily variation of hourly-averaged temperature values at Dome $\mathrm{C}$ during summer, autumn, spring, and winter. The temperature variability was similar in summer, autumn and spring, with a peak in the afternoon. However, a bias of around $20^{\circ} \mathrm{C}$ existed in the summer compared with autumn and spring. The maximum and minimum temperatures in summer were $-22^{\circ} \mathrm{C}$ and $-35^{\circ} \mathrm{C}$.
In autumn and spring the maximum temperature was $-42^{\circ} \mathrm{C}$, the minimum temperature $-53^{\circ} \mathrm{C}$. The amplitude of the diurnal temperature variation was $c .10^{\circ} \mathrm{C}$ during summer, spring and autumn. During winter, the average temperature was almost constant at a value of around $-60^{\circ} \mathrm{C}$. The largest standard deviation values were observed during the winter, spring and autumn $\left(5-8^{\circ} \mathrm{C}\right)$ due to the presence of the warming events. During summer the standard deviation was c. $5^{\circ} \mathrm{C}$ all day.

Temperature profiles are fundamental to the determination of the atmospheric static stability conditions during the year. Temperature profiles, with a temporal resolution of ten minutes and a spatial resolution varying between 10 and $25 \mathrm{~m}$, were measured by using the Microwave Radiometer (MPT-5P) described by Argentini \& Pietroni (2010). Figure 6 shows the diurnal-averaged, daily-averaged and nocturnalaveraged profiles for summer, autumn, winter and spring in the vertical range $0-300 \mathrm{~m}$. Unstable to neutral-stability conditions occurred in summer when the angle of the sun elevation was at its maximum. For all the other hours/seasons, the profiles were typical of a stably stratified boundary layer. The strongest temperature inversions occurred in winter. Under stable conditions, the temperature profiles showed a ground based inversion of $5^{\circ} \mathrm{C}$ per $100 \mathrm{~m}$ during summer and $20^{\circ} \mathrm{C}$ per $100 \mathrm{~m}$ during winter.

Figure 7 shows the distribution of the occurrence frequency of the potential temperature gradients at every MTP-5P level up to $150 \mathrm{~m}$ for summer and winter. The gradients ranged between -0.1 and $0.3^{\circ} \mathrm{C} \mathrm{m}^{-1}$ in summer and between -0.08 and $0.95^{\circ} \mathrm{C} \mathrm{m}^{-1}$ during winter. In both cases, but especially during the winter, the largest gradients occurred below $40 \mathrm{~m}$. This result is in general agreement with the observations made by Agabi et al. (2006) and 

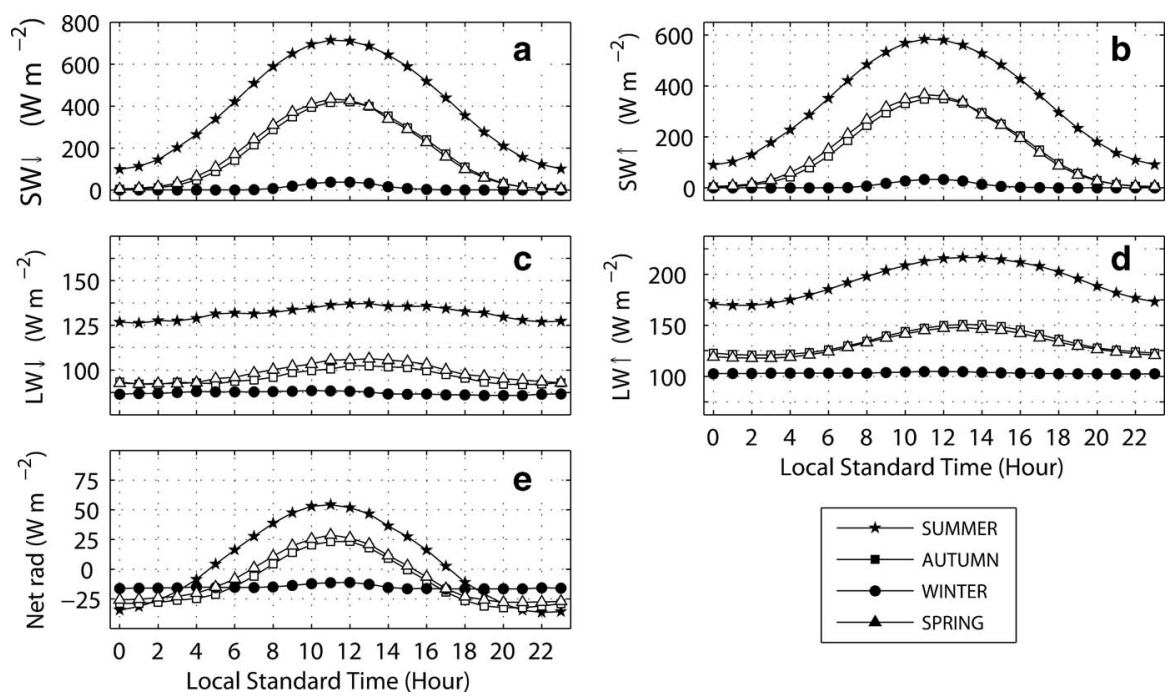

Fig. 9. Average daily cycle of hourlyaveraged radiative budget components during the STABLEDC project. a. Shortwave radiation down ( $\mathrm{SW} \downarrow$ ), b. shortwave radiation up ( $\mathrm{SW} \uparrow$ ), c. longwave radiation down ( $\mathrm{LW} \downarrow$ ), d. longwave radiation up ( $\mathrm{LW} \uparrow)$, and e. net radiation. Summer (star), autumn (square), winter (dot) and spring (triangle).
Aristidi et al. (2005a) in a study of the astronomical seeing at Dome C.

\section{Radiation budget components}

The Earth's atmosphere, cloud cover, surface albedo, latitude, season, and time of day affect the amount of the incoming shortwave radiation. The net radiation (Rnet) is the balance between the incoming (solar) and outgoing (terrestrial) radiation, both of which vary with latitude and season. Rnet may be decomposed as follows:

$$
\mathrm{Rnet}=\mathrm{SW} \downarrow-\mathrm{SW} \uparrow+\mathrm{LW} \downarrow-\mathrm{LW} \uparrow,
$$

where SW $\downarrow$ and $\mathrm{SW} \uparrow$ are the incoming and the reflected short wave radiation, and $\mathrm{LW} \downarrow$ and $\mathrm{LW} \uparrow$ are the incoming and outgoing longwave radiation. After quality-checking, the radiative fluxes have been weekly-averaged (one point is the average over a week). The annual behaviour of SW $\downarrow$ and $\mathrm{SW} \uparrow$ and the radiative flux at the top of the atmosphere $\left(\mathrm{R}_{\mathrm{TOA}}\right)$, the $\mathrm{LW} \downarrow$ and $\mathrm{LW} \uparrow$, and Rnet are shown in Fig. 8. The SW $\downarrow$ reached its peak value during the summer $\left(400 \mathrm{~W} \mathrm{~m}^{-2}\right)$ and decreased to $50 \mathrm{~W} \mathrm{~m}^{-2}$ at the beginning of winter. The values of the $\mathrm{LW} \downarrow$ ranged between $200 \mathrm{~W} \mathrm{~m}^{-2}$ in summer and $70 \mathrm{~W} \mathrm{~m}^{-2}$ in winter. The seasonal variation of $\mathrm{LW} \uparrow$ reflects the cycle of the surface temperature with maximum values of $\approx 200 \mathrm{~W} \mathrm{~m}^{-2}$ during the summer and minimum values of $\approx 100 \mathrm{~W} \mathrm{~m}^{-2}$ during the winter. During the summer, the absorption of shortwave radiation helps in reducing the surface inversion strength. During the winter, due to the annual minimum of the solar radiation, the Rnet variability is dominated by the longwave radiation and the radiation balance is always negative. Surface based inversions were observed all the time, the gradient of the surface based inversions decreasing only during the warming events as a consequence of the increase of surface temperature.
The hourly-averaged diurnal cycles of radiative budget components in summer, autumn, winter and spring are shown in Fig. 9. The peaks of the SW $\downarrow$ always occurred around noon. During summer, the peak value was $800 \mathrm{~W} \mathrm{~m}^{2}$, which decreased to $400 \mathrm{~W} \mathrm{~m}^{-2}$ in spring and autumn, while during winter the $\mathrm{SW} \downarrow$ was zero. The $\mathrm{SW} \uparrow$ presented a similar behaviour, but with lower values, due to the surface albedo. The LW $\downarrow$ also showed a diurnal variation; its value ranging between 87 and $107 \mathrm{~W} \mathrm{~m}^{-2}$ during autumn and spring, and between 125 and $137 \mathrm{~W} \mathrm{~m}^{-2}$ in summer. No variation was shown during winter. A pronounced diurnal cycle of the $\mathrm{LW} \uparrow$ was observed for all seasons with the exception of the winter months. In summer, this diurnal variability was consistent with the hypothesis of a convective boundary layer given by Mastrantonio et al. (1999), Argentini et al. (2005) and King et al. (2006). During the summer, Rnet was positive between $05 \mathrm{~h} 00$ and $17 \mathrm{~h} 00 \mathrm{LST}$, the interval with positive Rnet values reducing to $07 \mathrm{~h} 00-15 \mathrm{~h} 00 \mathrm{LST}$ during spring and autumn. During the polar night, Rnet was always negative.

\section{Summary and conclusions}

A field experiment from December 2004 to February 2005 at the French-Italian Concordia Station at Dome C aimed to monitor the behaviour of the meteorological boundary layer processes through a complete year. The main results can be summarized as follows:

1) At Dome $\mathrm{C}$ most of the time the strongest winds blow from the continental regions $\left(180^{\circ}-210^{\circ}\right)$. These winds are due to gravity flows from the inner plateau regions south of Dome C. The highest percentage and persistence of these flows are observed during the winter when strong, long-lived, surface-based inversions dominate all over the continent. 
2) The temperature distribution shows two maxima. The maximum centred between $-25^{\circ} \mathrm{C}$ and $-35^{\circ} \mathrm{C}$ corresponds to the summer temperatures, while the one between $-55^{\circ} \mathrm{C}$ and $-60^{\circ} \mathrm{C}$ includes most of the winter values. The annual trend shows a typical coreless winter perturbed by warming events. The warming events, mostly observed during the winter, can lead to an average rise of the near surface temperature of the order of $10^{\circ} \mathrm{C}$, which may strongly affect the radiative balance and the atmospheric circulation. As expected, a diurnal cycle is not observed during winter (average diurnal value $-55^{\circ} \mathrm{C}$ ). A daily cycle is observed during summer (the temperature ranges between $-35^{\circ} \mathrm{C}$ and $-25^{\circ} \mathrm{C}$ ), autumn and spring (temperatures range between $-50^{\circ} \mathrm{C}$ and $-45^{\circ} \mathrm{C}$ ) with a peak value around $14 \mathrm{~h} 00 \mathrm{LST}$.

3) During winter there are hourly-averaged wind speeds above $6 \mathrm{~m} \mathrm{~s}^{-1}$, coincident with warming events. These winds result from large-scale flows blowing from the eastern and western coasts of Antarctica $\left(300^{\circ}-330^{\circ}\right.$ and $90^{\circ}-150^{\circ}$ sectors).

4) The circulation at the surface during the summer is affected, especially in daytime, by the synoptic circulation. The wind speed oscillates during the day, with values increasing in the afternoon. In the afternoon a convective layer develops, leading to the increase of the wind speed due to the transfer of momentum from the upper layers towards the surface.

5) Average temperature gradients of the order of $20^{\circ} \mathrm{C}$ per $100 \mathrm{~m}$ are observed during the winter. On average, in spring the temperature gradients are larger than in autumn. In summer the temperature gradient is $c .5^{\circ} \mathrm{C}$ per $100 \mathrm{~m}$ during the night, while during the day a weak convective boundary layer is observed.

6) There is a shallow mixing layer of $c .30-40 \mathrm{~m}$ depth during winter. A weak convective boundary layer occurs during the day time in summer.

7) The daily cycle of the incoming shortwave radiation has a maximum between $11 \mathrm{~h} 00$ and $12 \mathrm{~h} 00$ LST. The peak values are around $740 \mathrm{~W} \mathrm{~m}^{-2}, 440 \mathrm{~W} \mathrm{~m}^{-2}$ and $50 \mathrm{~W} \mathrm{~m}^{-2}$ in summer, spring/autumn and winter respectively. The average downward longwave radiation oscillates between $125 \mathrm{~W} \mathrm{~m}^{-2}$ during the night and $137.5 \mathrm{~W} \mathrm{~m}^{-2}$ during the day. In spring and autumn, the night-day variation remains the same but the value is reduced to $11 \mathrm{~W} \mathrm{~m}^{-2}$.

8) The hourly-averaged net radiation is always negative from February-November with values below $-20 \mathrm{~W} \mathrm{~m}^{-2}$. During summer it is positive between 05h00 LST and 17h00 LST with a peak value of $50 \mathrm{~W} \mathrm{~m}^{-2}$. In autumn and spring positive values are observed between $08 \mathrm{~h} 00$ and $15 \mathrm{~h} 00$ LST with a peak of $25 \mathrm{~W} \mathrm{~m}^{-2}$.
Measurements are under way with a surface layer mini sodar in order to monitor, with a resolution of a few metres, the evolution of the stable mixing layer during winter.

\section{Acknowledgements}

This research was supported by the Piano Nazionale Ricerche in Antartide (PNRA) in the framework of French-Italian projects for Dome C. The authors wish to thank the logistics staff at Concordia for their support during the fieldwork. The authors thank A. Conidi for the technical work which has been provided in the realization of the STABLEDC project and Dr D. Cavallaro for editing the paper. The constructive comments of the reviewers are gratefully acknowledged.

\section{References}

Agabi, A., Aristidi, E., Azouit, M., Fossat, E., Martin, F., Sadibekova, T., Vernin, J. \& Ziad, A. 2006. First whole atmosphere night time seeing measurements at Dome C, Antarctica. The Publications of the Astronomical Society of the Pacific, 118, 344-348.

Argentini, S. \& Pietroni, I. 2010. An integrated observing system for boundary layer monitoring at Concordia Station, Antarctica. In Cimino, N., Marzano, F. \& Visconti, G., eds. Integrated ground-based observing systems. Part 2. New York: Springer, 199-208.

Argentini, S., Viola, A., Sempreviva, A. \& Petenko, I. 2005. Summer boundary-layer height at the plateau site of Dome C, Antarctica. Boundary-Layer Meteorology, 115, 409-422.

Argentini, S., Petenko, I., Mastrantonio, G., Bezverkhnil, V. \& ViolA, A. 2001. Spectral characteristics of East Antartica meteorological parameters during 1994. Journal of Geophysical Research, 106, 12 463-12476.

Aristidi, E., Agabi, A., Fossat, E., Azouit, M., Martin, F., Sadibekova, T., Travouillon, T., Vernin, J. \& Ziad, A. 2005a. Site testing in summer at Dome C, Antarctica. Astronomy and Astrophysics, 444, 651-659.

Aristidi, E., Agabi, A., Azouit, M., Fossat, E., Vernin, J., Travouillon, T., Lawrence, J.S., Meyer, C., Storey, J.W.V., Halter, B., Roth, W.L. \& WALDEN, V. 2005b. An analysis of temperature and wind speed above Dome C, Antarctica. Astronomy and Astrophysics, 430, 739-746.

Bintanja, R. \& VAN DEN BRoeke, M.R. 1995. The surface-energy balance of Antarctic snow and blue ice. Journal of Applied Meteorolology, 34, 902-926.

CARroll, J.J. 1982. Long-term means and short-term variability of the surface energy balance components at the South Pole. Journal of Geophysical Research, 87, 4277-4286.

Carroll, J.J. \& Fitch, B.W. 1981. Effects of solar elevation and cloudiness on snow albedo at the South Pole. Journal of Geophysical Research, 86, 5271-5276.

Connolley, W.M. 1996. The Antarctic temperature inversion. International Journal of Climatology, 16, 1333-1342.

Dalrymple, P.C. 1966. A physical climatology of the Antarctic Plateau. Antarctic Research Series, 9, 195-231.

Dutton, E.G., Stone, R.S., Nelson, D.W. \& Mendonca, B.G. 1991. Recent interannual variations in solar radiation, cloudiness and surface temperature at the South Pole. Journal of Climate, 4, 848-858.

GeIssLER, K. \& Masciadri, E. 2006. Meteorological parameters analysis above Dome $\mathrm{C}$ using data from the European Centre for Medium-Range Weather Forecast. Publications of the Astronomical Society of the Pacific, 118, 1048-1065.

Hagelin, S., Masciadri, E., Lescaux, F. \& Stoesz, J. 2008. Comparison of the atmosphere above South Pole, Dome C and Dome A: first attempt. Monthly Notices of the Royal Astronomical Society, 387, 1499-1510. 
Hudson, S.R. \& Brandt, R.E. 2005. A look at the surface based temperature inversion on the Antarctic plateau. Journal of Climate, 18, $1673-1696$.

Jouzel, J. \& Merlivat, L.J. 1984. Deuterium and oxygen 18 in precipitation modelling of the isotopic effects during snow formation. Journal of Geophysical Research, 89, 11 749-11757.

KADYGRov, E.N. \& PICK, D.R. 1998. The potential for temperature retrieval from an angular-scanning single-channel microwave radiometer and some comparisons with in situ observations. Meteorological Applications, 5, 393-404.

King, J.C. \& Connolley, W.M. 1997. Validation of the surface energy balance over the Antarctic ice sheets in the UK Meteorological Office unified climate model. Journal of Climate, 10, 1273-1287.

King, J.C. \& Turner, J. 1997. Antarctic meteorology and climatology. Cambridge: Cambridge University Press, 409 pp.

King, J.C., Argentini, S. \& Anderson, P.S. 2006. Contrasts between the summertime surface energy balance and boundary layer structure at Dome C and Halley stations, Antarctica. Journal of Geophysical Research, 10.1029/2005jd006130.

Lascaux, F., Masciadri, E., Hagelin, S. \& Stoesz, J. 2009. Mesoscale optical turbulence simulations at Dome C. Monthly Notices of the Royal Astronomical Society, 398, 1093-1104.

Lawrence, J.S., Ashley, M.C.B., Tokovinin, A. \& Trouvillon, T. 2004. Exceptional astronomical seeing conditions above Dome $\mathrm{C}$ in Antarctica. Nature, 431, 278-281.

Lettau, H.H. \& Schwerdtfeger, W. 1967. Dynamics of the surface-wind regime over the interior of Antarctica. Antarctic Journal of the United States, 2 (5), 155-158.

Marks, R.D., Vernin, J., Azouit, M., Manigault, J.F. \& Clevelin, C. 1999. Measurement of optical seeing on the high Antarctic plateau. Astronomy and Astrophysics Supplement Series, 134, 161-172.

Mastrantonio, G., Malvestuto, V., Argentini, S., Georgiadis, T. \& Viola, A. 1999. Evidence of a convective boundary layer developing on the Antarctic Plateau during the summer. Meteorology and Atmospheric Physics, 71, 127-132.

NefF, W.D. 1999. Decadal time scale trends and variability in the tropospheric circulation over the South Pole. Journal of Geophysical Research, 104, 217-251.

Ohtake, T. 1978. Atmospheric ice crystals at the South Pole in summer. Antarctic Journal of the United States, 13 (4), 174-175.
Phillpot, H.R. \& Zillman, J.W. 1970. The surface temperature inversion over the Antarctic continent. Journal of Geophysical Research, 75, 4161-4169.

Pietroni, I., Argentini, S., Petenko, I. \& Sozzi, R. 2012. Measurements and parametrizations of the atmospheric boundary-layer height at Dome C, Antarctica. Boundary-Layer Meteorology, 143, 189-206.

Schwerdtfeger, P. \& Weller, G. 1977. Radiative heat transfer processes in snow and ice. Antarctic Research Series, 25, 35-39.

Stanhill, G. \& Cohen, S. 1997. Recent changes in solar irradiance in Antarctica. Journal of Climate, 10, 2078-2086.

Stone, R.S. 1993. Properties of austral winter clouds derived from radiometric profiles at the South Pole. Journal of Geophysical Research, 98, 12 961-12971.

Stone, R.S. \& KAHL, J.D. 1991. Variations in boundary layer properties associated with clouds and transient weather disturbance at the South Pole during winter. Journal of Geophysical Research, 96, 5137-5144.

Stone, R.S., Dutton, G. \& DeLuisi, J.J. 1990. Surface radiation and temperature variations associated with cloudiness at the South Pole. Antarctic Journal of the United States, 24 (5), 230-232.

Van As, D., VAn den Broeke, M.R. \& VAn DE WaL, R. 2005b. Daily cycle of the surface layer and energy balance on the high Antarctic Plateau. Antarctic Science, 17, 121-133.

Van As, D., van den Broeke, M.R., Reijmer, C. \& van De Wal, R. 2005a. The summer surface energy balance of the high Antarctic plateau. Boundary-Layer Meteorology, 115, 289-317.

VAn den WaL, R.S.W. \& Oerlemans, J. 1997. Modelling the short-term response of the Greenland ice sheet to global warming. Climate Dynamics, 13, 733-744.

Wild, M., Ohmura, A. \& Gilgen, H. 1995. Validation of general circulation model radiative fluxes using surface observations. Journal of Climate, 8, 1309-1324.

Wiscombe, W. \& Warren, S. 1980. A model for the spectral albedo of snow. I: Pure snow. Journal of Atmospheric Science, 37, 2712-2733.

Zhou, M., Zhang, Z., Zhong, S., Lenschow, D., Hsu, H.-M., Sum, B., GAO, Z., LI, S., Bian, X. \& Yu, L. 2009. Observations of near-surface wind and temperature structures and their variation with topography and latitude in East Antarctica. Journal of Geophysical Research, 10.1029/ 2008JD011611. 